\section{Oral Health Related Quality of Life in an Adult Jamaican Population}

Michelle Antonette Brown ${ }^{1}$, Candace Lockhart ${ }^{1}$, Biney Thomas ${ }^{1}$, Rafaela Soares Rech ${ }^{2}$

${ }^{1}$ School of Dentistry, University of the West Indies, Faculty of Medical Sciences, Mona, Jamaica

${ }^{2}$ Department of Preventive and Social Dentistry, Faculty of Dentistry, Universidade Federal do Rio Grande do Sul, Porto Alegre/RS, Brazil.

\section{Corresponding author}

Michelle Antonette Brown

School of Dentistry, University of the West Indies, Faculty of Medical Sciences, Mona, Jamaica

Email: michelle.brown11@uwimona.edu.jm

DOI: $10.48107 / C M J .2020 .12 .009$

Copyright:

(c) (1)

This is an open access article under the terms of the Creative Commons Attribution License which permits use, distribution and reproduction in any medium, provided the original work is properly cited.

\section{ABSTRACT \\ Objectives}

The aim of this study is to evaluate the impact of sociodemographic characteristics, oral health status and behaviours on Oral Health Related Quality of Life (OHRQoL) on an adult Jamaican population.

\section{Methods}

Adults who presented for treatment at the UWI Mona Dental Polyclinic participated in this cross-sectional study. Participants responded to a structured questionnaire consisting of sociodemographic and oral hygiene habits and were also examined for the presence of decayed, missing and filled teeth (DMFT). OHRQoL was assessed using the Oral Health Impact Profile (OHIP-14) questionnaire. Descriptive statistical analysis, univariate and multiple Poisson Regression with robust variance were performed to identify the factors impacting OHRQOL.

\section{Results}

The study sample consisted of 120 adults between the ages of 18-59 years. The mean OHIP-14 score was 9.81 $( \pm 9.06), 24 \%$ presented impaired OHRQoL and 76\% presented frequent impaired OHRQoL. The most prevalent domain was physical pain $(80 \%)$ followed by psychological discomfort (59\%) and the mean DMFT score was $9.92( \pm 8.78)$. In the adjusted logistic regression, participants aged between 29-46 years (PR 0.58 , CI $0.37-0.90, p=0.016)$ and the use of fluoride toothpaste (PR 0.52, 95\%, CI 0.35- 0.77, $\mathrm{p}=0.001$ ) were negatively associated with OHRQoL.

\section{Conclusion}

Physical pain was the dimension that most impacted domain in OHRQoL. The most negative OHRQoL was associated with the 29 to 46 years age-group and the use of fluoride toothpaste. These findings are important for oral health strategies in this population. 


\section{INTRODUCTION}

Oral Health Related Quality of Life (OHRQoL) is an instrument that was created as a means to subjectively quantify the psychosocial and emotional burden of oral illness amongst various populations by investigating patients' perceptions of their oral health and its impact on their day-to-day lives. ${ }^{1}$

The Oral Health Impact Profile (OHIP) is a framework designed to assess the importance of oral health to patients and its impact on their overall health in the physical, psychological, and social domains. ${ }^{2}$ It was originally constructed to assess the impact of oral health on quality of life and included 49 questions (OHIP-49), but was later deemed to be inappropriate in some health research settings. $^{3}$ Thus, a shortened version was created (OHIP-14) which is being used to assess the impact of oral health through fourteen questions analysing the functional limitation, physical pain, psychological discomfort, physical disability, psychological disability, social disability and handicap domains. ${ }^{4}$ The OHIP-14 has been shown to have better validity, reliability and precision. ${ }^{4}$ The World Health Organization (WHO) defines health as the complete state of physical, mental and social well-being and not just the absence of disease. ${ }^{5}$ Therefore, this model is important in bridging the gap in oral healthcare and assisting in the development of better health policies that are inclusive of clinical outcomes of disease and patient experience.

There have been multiple studies in different populations which have shown the association of sociodemographic factors, general health status and oral health conditions and their impact in OHRQoL. ${ }^{1,2,4,6-10}$ However, there is very little information regarding the impact of oral health and OHRQoL in Jamaica and the Caribbean region. Collins et al, in a multicentre study done in three Caribbean cities (Kingston, Jamaica; Santo Domingo, Dominican Republic and San Juan, Puerto Rico), showed that factors such as gingival health, smoking, frequency of dental visits and the presence of chronic diseases impacted the OHRQoL. ${ }^{10}$ Notwithstanding this publication, more studies are needed in Jamaica and the Caribbean region to ascertain information about oral health status, including decayed, missing and filled teeth (DMFT) and its impact on OHRQoL. With this background, the aim of this cross-sectional study was to evaluate the impact of sociodemographic characteristics, oral health status and behaviours of adult Jamaican population on their OHRQoL.

CMJ | Published online on December 20th, 2020

\section{METHODS}

Prior to carrying out this study, approval was obtained from The University of the West Indies (UWI) Ethics Committee. Written informed consent was obtained from all the participants.

\section{Study design}

This was designed as a cross-sectional study at the UWI Mona Dental Polyclinic (UMDP). Inclusion criteria were individuals between the ages of 18 to 59 years who were receiving treatment at the UMDP. Exclusion criteria were individuals who:

presented to the UMDP with pain that prevented them from speaking with ease

were unable to provide responses to all the questions have hearing impairment and/or speaking difficulty were not of Jamaican nationality

presented emergency oral conditions such as Lud-

wig's angina and space infections that extend to throat causing dyspnoea, dysphagia and/or dysarthria and

were not willing to participate in the study and/or not willing to sign the consent form.

Data collection was carried out by five trained investigators (C.L., B.T., L.D., A.O., S.W.). Training and calibration were carried out in two steps in accordance with the World Health Organization, 2013. ${ }^{11}$ Standardisation of the diagnostic criteria for caries was initially done by discussion and agreement according to the decayed, missing and filled teeth (DMFT) index. Inter-examiner calibration was then carried out on twenty individuals using the DMFT index by the benchmark investigator (M.A.B) (whose experience was agreed to be the 'gold-standard'). Intra-examiner calibration was then carried out on these same patients after a two-week interval. Kappa values for inter-examiner and intra-examiner agreement were between $0.86-0.93$.

\section{Data collection and questionnaires}

A trained (calibrated) examiner examined all teeth under natural light with ball-point probes and mirrors with reference to the DMFT index. ${ }^{11}$

A structured questionnaire was administered to all the participants by the trained examiner in a face-to-face interview. The questionnaire included sociodemographic data such as: age, self- reported race (African descent, Caucasian, Mixed, Indian, Chinese); marital status (single, 
married, divorced, widowed); level of education (primary level, secondary level, tertiary level, skilled/technical course); employment status (yes/no), student (yes/no); monthly income (one minimum wage, two minimum wages, three or more minimum wages). Minimum wage was estimated to be $\$ 7000$ JMD (approximately \$206 USD monthly). Data regarding oral hygiene habits were also collected and these included: brushing of teeth (yes/no), frequency, use of a fluoride toothpaste (yes/no) and dental floss (yes/no). Data pertaining to reason of visit were also collected (toothache, check-up/oral prophylaxis, periodontal treatment, making a crown/bridge/prothesis, tooth extraction, root canal treatment, fillings for caries, fillings for aesthetic reasons and other aesthetic treatment).

A trained examiner administered the Oral Health Impact Profile 14 (OHIP-14). The OHIP-14 evaluates seven dimensions with two questions each that take into consideration functional limitation, physical pain, psychological discomfort, physical disability, psychological disability, social disability, and handicap.

Participants rated their OHRQoL on a scale of $0-4(0=$ never, $1=$ hardly ever, $2=$ occasionally, 3 = fairly often, 4 = very often) corresponding to up to twelve months before the interview. The impact of OHRQoL was estimated according to the mean severity score (the sum of all ordinal responses ranging from 0-56) and also classified as the prevalence of persons reporting scores fairly often (score 3 ) and very often (score 4) who were termed as frequently impaired. ${ }^{6,12}$ Impaired persons included those who responded occasionally (score 2 ), fairly often (score 3) and very often (score 4). ${ }^{6}$

\section{Statistical analysis}

The outcome studied was the status of OHRQoL focusing on the poor quality of life. Analyses of the absolute and relative frequencies were conducted. Descriptive analyses by mean and standard deviation (SD) were also done. Poisson Regression with robust variance was used to calculate crude and adjusted prevalence ratios (PR) and their respective $95 \%$ confidence intervals (CI). The independent variables (sociodemographic and oral health behaviour) were added to the adjusted multivariate model and the variables with a $p$-value $\leq 0.2$ in the crude analysis were also considered. A significance level of $5 \%$ was adopted to retain variables in the model with a "backward" variable selection.
The linearity of the continuous variables was analysed to verify whether they maintained the assumption of linearity. In addition, the presence of multicollinearity was assessed using the variance inflation factor (VIF) estimates. Confounding variables were adjusted or eliminated to prevent overlapping results. For example, 'brushing of teeth' was removed from the analysis because of its interaction with 'use of fluoride toothpaste'. The statistical significance of the prevalence ratio indices was assessed using the Wald test. The goodness-of-fit of the model was assessed using the Hosmer-Lemeshow test. The data was analysed using SPSS v.21 software (Chicago: SPSS Inc).

\section{RESULTS}

A total of 124 persons participated in the study; however, four persons were excluded for having incomplete questionnaires or falling within the exclusion criteria, with a final sample size of 120 .

The mean age of the sample was $34.18 \pm 12.99$ (SD). Table 1 shows the descriptive characteristics of the study. The majority were males (71\%) between the ages of 18 23 years $(29 \%)$ and single $(72 \%)$. The most prevalent educational level was the secondary level (48\%); most participants were employed (59\%) and received three or more minimum wages monthly (35\%). Regarding oral health status, $12 \%$ had dental caries, $8 \%$ missing teeth due to dental caries and $7 \%$ presented with fillings. The majority of the participants practiced good oral hygiene habits and brushed their teeth (99\%), twice a day (73\%) with fluoride toothpaste (97\%) and used dental floss (61\%). The most common reason for visit to the dentist was to have a check-up / oral prophylaxis done (60\%). In relation to OHRQoL, the mean severity score was $\underline{9.8}$ $( \pm 9.06), 24 \%$ presented impaired OHRQoL, and $76 \%$ presented frequently impaired OHRQoL.

Table 2 describes the frequency of responses for individual items and the domains of the OHIP-14. Of the 14 items, the most prevalent was painful aching in the mouth $(70 \%)$ followed by uncomfortable to eat $(66 \%)$ and being self-conscious (59\%). Of the seven OHIP-14 domains, the most prevalent was physical pain (80\%) followed by psychological discomfort (59\%). Of note, $39 \%$ of the participants experienced none of the 14 items 
of the OHIP-14. Table 3 shows the crude and adjusted analyses for the variables. In the univariate analysis $(p<0.2)$, the following variables showed significance: age (24-28 and $\geq 47$ years), being a student, brushing of teeth, use of fluoride toothpaste, floss and reason for visit to the dentist. When adjusted for in the multivariate analysis, age 29-46 years old and use of fluoride toothpaste showed a negative association ( $P R=0.52(0.35-0.77)$ with impact in OHRQoL with a statistical significance $(p<0.05)$.

Table 1. Demographic and clinical characteristics $(n=120)$

\begin{tabular}{|c|c|c|c|c|}
\hline Variable & Sample & $\begin{array}{c}\text { OHIP-14 } \\
\text { scores } \\
\end{array}$ & $\begin{array}{l}\text { Impaired } \\
\text { OHRQoL }\end{array}$ & $\begin{array}{c}\text { Frequent Impaired } \\
\text { OHRQoL } \\
\end{array}$ \\
\hline & n (\%) & Mean ( $(\mathbf{S D})$ & n (\%) & n (\%) \\
\hline \multicolumn{5}{|l|}{ Sociodemographic variables } \\
\hline All & $\begin{array}{c}120 \\
(100.0 \%)\end{array}$ & $9.81( \pm 9.06)$ & $29(24.2 \%)$ & $91(75.8 \%)$ \\
\hline Age (18-23 years) & $35(29.2 \%)$ & $11.20( \pm 8.32)$ & $4(13.8 \%)$ & $31(34.1 \%)$ \\
\hline Black & $104(86.7 \%)$ & $9.60( \pm 8.67)$ & $25(86.2 \%)$ & $79(86.8 \%)$ \\
\hline Male & $85(70.8 \%)$ & $10.48( \pm 9.38)$ & $20(69.0 \%)$ & $65(71.4 \%)$ \\
\hline Single & $86(71.7 \%)$ & $10.04( \pm 9.09)$ & $19(65.5 \%)$ & $67(73.6 \%)$ \\
\hline $\begin{array}{l}\text { Education (Secondary level com- } \\
\text { pleted) }\end{array}$ & $57(47.5 \%)$ & $10.42( \pm 9,00)$ & $11(37.9 \%)$ & $46(50.5 \%)$ \\
\hline Employed & $71(59.2 \%)$ & $8.75( \pm 7.32)$ & $19(65.5 \%)$ & $52(57.1 \%)$ \\
\hline Student & $49(40.8 \%)$ & $10.18( \pm 10.02)$ & $9(31.0 \%)$ & $40(44.0 \%)$ \\
\hline Income $(\geq 3)$ & $42(35.0 \%)$ & $9.73( \pm 9.44)$ & $8(27.6 \%)$ & $34(37.4 \%)$ \\
\hline \multicolumn{5}{|l|}{$\begin{array}{l}\text { Oral Health Status (in number } \\
\text { of teeth) }\end{array}$} \\
\hline Sound & $\begin{array}{c}2591 \\
(67.47 \%)\end{array}$ & $9.60( \pm 8.77)$ & $29(24.4 \%)$ & $90(75.6 \%)$ \\
\hline$\overline{\mathrm{DT}}$ & $\begin{array}{c}477 \\
(12.42 \%)\end{array}$ & $10.37( \pm 9.07)$ & $19(20.9 \%)$ & $72(79.1 \%)$ \\
\hline MT & $307(7.99 \%)$ & $10.80( \pm 9.30)$ & $18(8.0 \%)$ & $49(80.0 \%)$ \\
\hline$\overline{\mathrm{FT}}$ & $271(7.06 \%)$ & $8.61( \pm 7.98)$ & $18(27.3 \%)$ & $48(72.7 \%)$ \\
\hline DMFT & $\begin{array}{c}1055 \\
(40.72 \%)\end{array}$ & $9.92( \pm 8.78)$ & $56(65.88 \%)$ & $169(65.25 \%)$ \\
\hline \multicolumn{5}{|l|}{ Oral Health Behaviour } \\
\hline Brushing of teeth & $119(99.2 \%)$ & $9.59( \pm 8.77)$ & $29(100.0 \%)$ & $90(98.9 \%)$ \\
\hline Fluoride toothpaste & $116(96.7 \%)$ & $9.53( \pm 8.76)$ & $29(100.0 \%)$ & $87(96.7 \%)$ \\
\hline $\begin{array}{l}\text { Frequency of brushing of teeth } \\
\text { (twice/day) }\end{array}$ & $88(73.3 \%)$ & $9.59( \pm 8.77)$ & $22(75.9 \%)$ & $66(72.5 \%)$ \\
\hline Dental floss & $73(60.8 \%)$ & $7.68( \pm 7.86)$ & $21(72.4 \%)$ & $52(57.1 \%)$ \\
\hline $\begin{array}{l}\text { Reason for visit to the dentist } \\
\text { Check-up/oral prophylaxis }\end{array}$ & $71(59.2 \%)$ & $6.74( \pm 6.64)$ & $21(72.4 \%)$ & $50(54.9 \%)$ \\
\hline
\end{tabular}

Abbreviations: DT- decayed teeth; MT - missing teeth; FT - filled teeth; DMFT -decayed, missing, filled teeth 


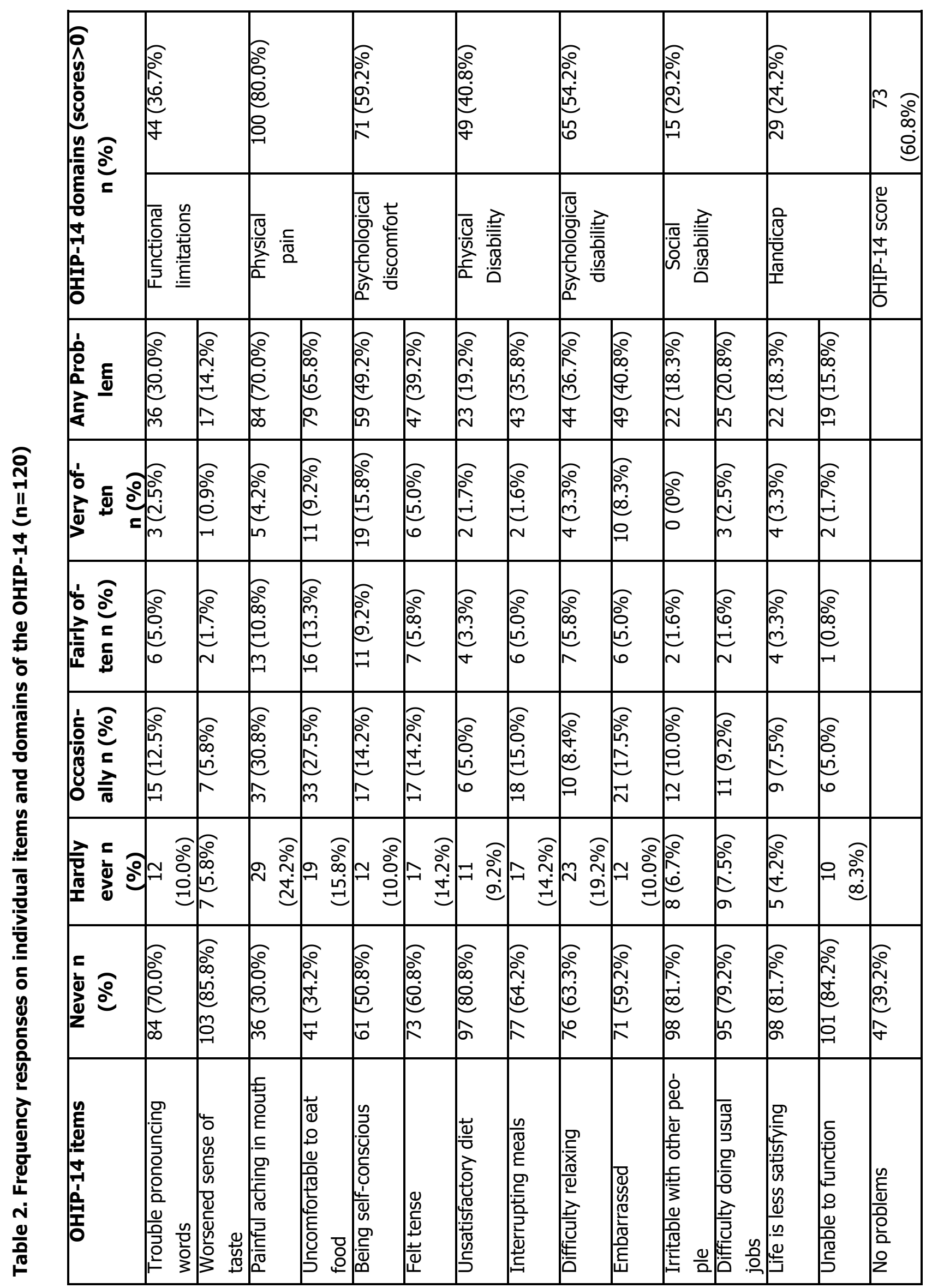


Table 3. Poisson regression and its crude and adjusted prevalence ratios (PR) for sociodemographic variables and oral health behaviour $(n=120)$

\begin{tabular}{|c|c|c|c|c|}
\hline Variable & $\begin{array}{l}\text { PR Crude }(95 \% \\
\text { CI }) \\
\end{array}$ & p-value & $\begin{array}{c}\text { PR Adjusted (95\% } \\
\text { CI) }\end{array}$ & $\begin{array}{c}\text { p- } \\
\text { value }\end{array}$ \\
\hline \multicolumn{5}{|l|}{$\begin{array}{l}\text { Sociodemographic varia- } \\
\text { bles }\end{array}$} \\
\hline \multicolumn{5}{|l|}{ Age } \\
\hline (18-23 years) - $1^{\text {st }}$ quartile & 1 & - & 1 & - \\
\hline (24-28 years) - $2^{\text {nd }}$ quartile & $0.96(0.78-1.17)$ & 0.658 & $0.93(0.73-1.19)$ & 0.567 \\
\hline (29-46 years) - $3^{\text {rd }}$ quartile & $0.64(0.45-0.89)$ & 0.009 & $0.58(0.37-0.90)$ & 0.016 \\
\hline $\begin{array}{l}\text { (47 years or more) }-4^{\text {th }} \text { quar- } \\
\text { tile }\end{array}$ & $0.82(0.634-1.05)$ & 0.120 & $0.73(0.49-1.07)$ & 0.102 \\
\hline \multicolumn{5}{|l|}{ Race } \\
\hline African & 1 & - & - & - \\
\hline Other & $0.99(0.73-1.34)$ & 0.934 & - & - \\
\hline \multicolumn{5}{|l|}{ Sex } \\
\hline Male & 1 & - & - & - \\
\hline Female & $1.03(0.82-1.29)$ & 0.803 & - & - \\
\hline \multicolumn{5}{|l|}{ Marital Status } \\
\hline Single & 1 & - & - & - \\
\hline Other & $0.91(0.71-1.16)$ & 0.429 & - & - \\
\hline \multicolumn{5}{|l|}{ Education } \\
\hline Until Secondary Level & 1 & - & - & - \\
\hline Until Skilled/Technical course & $0.85(0.69-1.05)$ & 0.847 & - & - \\
\hline \multicolumn{5}{|l|}{ Student } \\
\hline Yes & 1 & - & 1 & - \\
\hline No & $1.14(0.93-1.38)$ & 0.200 & $0.88(0.67-1.14)$ & 0.325 \\
\hline \multicolumn{5}{|l|}{ Employment status } \\
\hline Employed & 1 & - & - & - \\
\hline Unemployed & $0.92(0.75-1.12)$ & 0.414 & - & - \\
\hline \multicolumn{5}{|l|}{ Income (minimum salary) } \\
\hline 0 & 1 & - & - & - \\
\hline 1 & $0.82(0.58-1.18)$ & 0.288 & - & - \\
\hline 2 & $0.89(0.647-1.23)$ & 0.487 & - & - \\
\hline$\geq 3$ & $0.94(0.75-1.18)$ & 0.596 & - & - \\
\hline \multicolumn{5}{|l|}{ Oral Health Behaviour } \\
\hline DMFT & $1.15(0.64-2.03)$ & 0.645 & - & - \\
\hline Decayed teeth & $1.13(0.86-1.48)$ & 0.366 & & \\
\hline Missing teeth & $1.12(0.87-1.44)$ & 0.371 & & \\
\hline
\end{tabular}




\begin{tabular}{|l|c|c|c|c|}
\hline Brush* & & & & \\
\hline No & 1 & - & - & - \\
\hline Yes & $0.76(0.68-0.84)$ & $<0.001$ & - & \\
\hline $\begin{array}{l}\text { Number of times teeth } \\
\text { brushed per day }\end{array}$ & & & & \\
\hline Until 2 & 1 & - & & \\
\hline More than 2 & $0.96(0.77-1.19)$ & 0.715 & & \\
\hline Fluoride toothpaste & & & & \\
\hline No & 1 & - & & - \\
\hline Yes & $0.75(0.68-0.83)$ & $<0.001$ & $0.52(0.35-0.77)$ & 0.001 \\
\hline Floss & & & & \\
\hline No & 1 & - & & - \\
\hline Yes & $0.86(0.71-1.04)$ & 0.125 & $0.94(0.76-1.15)$ & 0.533 \\
\hline $\begin{array}{l}\text { Reason for visit to the } \\
\text { dentist }\end{array}$ & & & & \\
\hline Check-up/oral prophylaxis & 1 & - & & 1 \\
\hline Other & $1.18(0.98-1.44)$ & 0.083 & $1.10(0.90-1.34)$ & 0.339 \\
\hline
\end{tabular}

\section{DISCUSSION}

This study evaluated the impact of oral health on the quality of life of an adult Jamaican population. Currently, to the best of our knowledge, there is very little information regarding the OHRQoL of Jamaican adults or other neighbouring Caribbean adult populations.

Most of the participants in this study were employed, educated and received three or more minimum wages. It is possible to indirectly deduce that these individuals could afford dental treatment and were interested in having good oral health. It has been shown that lower levels of education and socio-economic status are more likely to be correlated with worse oral health. ${ }^{13,14}$

Study participants had a high prevalence of healthy teeth $(67 \%)$ and dental check-ups/ oral prophylaxis (59\%) was the main reason for seeking dental treatment, demonstrating good preventive behaviour. One previous study found that reports of multiple oral health problems were associated with not having recent preventive visits to the dentist and brushing less than twice daily. ${ }^{15}$

The participants in the study showed excellent oral hygiene behaviour, whereby the vast majority brushed their teeth twice a day, used dental floss and sought oral examinations/ oral prophylaxis. A study carried out in the
Dominican Republic that assessed the determinants of oral hygiene behaviour similarly found good oral hygiene behaviour where the habit and frequency of brushing of teeth and the use of fluoride toothpaste were concerned. ${ }^{15}$ However, it was heartening to find that the use of interdental cleaning methods such as the use of dental floss $(61 \%)$ in the present study was more prevalent than in the study from Dominican Republic (26\%).

The results of this study revealed that oral health impacts the quality of life of the Jamaican subjects included in the study, as the mean severity score was 9.8. This was substantially higher than seen in adults from other representative samples in Caribbean countries such Puerto Rico, the Dominican Republic and even Jamaica where the mean summary score was $7.2{ }^{10}$ Frequent impairment was substantially greater than was seen in a number of other populational studies such as Australia, United States of America, Myanmar, Czech Republic and Norway. $6,8,9,17$

The most prevalent domains in the OHIP-14 reported in this present study were physical pain and psychological discomfort. This finding was consistent with the findings in other populational studies. ${ }^{6-8}$ The prevalence of these 
domains shows that these are aspects that should be taken into consideration when planning dental public health strategies for populations similar to the present study.

This study presents important findings for preventing a reduction in the oral health related quality of life. The brushing of teeth with a fluoride toothpaste was shown to be significantly protective in this study which can be correlated with the fact that it is well known that the use of a fluoride toothpaste is a key factor in the prevention of dental caries. ${ }^{18}$ Similar to the present study, a study by Htun and Peltzer in 2019 also found that using fluoride toothpaste had a negative association with OHRQoL. ${ }^{6}$

It was shown earlier that health-related quality of life worsens as age increases. ${ }^{2}$ The present study included individuals who attended a private university clinic who were generally young in age with favourable oral health, good oral hygiene and mainly visited the dentist for preventive care. Individuals between $29-46$ years old presented a negative association with impaired OHRQoL. These individuals are therefore protected from having a poor OHRQoL. Additionally, the use of fluoride toothpaste contributes to the lower prevalence (negative association) of impaired OHRQoL in this population. It has been shown that a Jamaican population presented the worst OHRQoL when compared to populations in Puerto Rico and Santo Domingo. ${ }^{10}$ This further highlights the importance of using fluoride not only in preventing oral health problems, but also for the improvement of the quality of life of individuals.

Most of the outcome measures in dentistry consider only the clinical aspects of oral health by equating them with the absence of disease. This normative approach only contemplates one aspect of general health. As a result, more studies have included subjective evaluations of function and well-being. ${ }^{19}$ This is coherent with the concept of health which refutes the traditional biomedical model of health and disease that only regards the clinical aspect. ${ }^{12}$ Therefore, it is important to account for these measures in regions that have very little information about oral health and how it could impact on the quality of life. Based on the findings of this study, it is also important to target populations and design strategies to cater to those who do not have the habit of brushing their teeth with a fluoride toothpaste and also to those outside of the 29-46 years age group.
This study presents important contributions for the improvement of OHRQoL, however, some limitations attributable to the design and descriptive nature of the study must be taken into account. The small sample size affects the generalisability of the results and it is recommended that future nationwide studies in the area be conducted. Additionally, biases such as social desirability and memory bias could have affected the validity of the findings of this study.

Though this study did not use the severity score to evaluate OHRQoL and may have potentially underestimated the impact of oral health on quality of life, comparisons could still be made with other neighbouring populations using the mean severity score. ${ }^{10}$ However, in the current study, 'frequentlyimpaired' and 'impaired' OHRQoL scores were used to estimate the domains of the OHRQoL that would be more likely to be chronic and thus frequently repeated. ${ }^{6}$ This, therefore, would be more important from a public health point of view to aid in planning strategies and implementing health programmes. ${ }^{12}$

\section{CONCLUSION}

Oral Health Related Quality of Life (OHRQoL) is an important measurement in dental public health. In Jamaica, physical pain has been found to be the dimension that most impacted OHRQoL and participants aged between 29-46 years and use of fluoride toothpaste were negatively associated with the worst OHRQoL. This study demonstrated that the importance of the use of fluoride is not only for oral health promotion, but also for a better quality of life.

Ethical Approval statement: Ethical approval was obtained from the Ethics Committee of the University of the West Indies.

Informed Consent statement: Written, informed consent was obtained from all participants.

Conflict of Interest statement: Nothing to declare. Funding Statement: No funding.

Author Contributions: Brown MA was involved in the initial conception, design of the study, collection and interpretation of data and preparation and final revision 
of the manuscript. Lockhart $\mathrm{C}$ was involved in the collection of data, preparation and final revision of the manuscript. Thomas B assisted in the conception and design of the study, assisted with data collection and the final revision of the manuscript. Rech RS was involved with the interpretation and analysis of data, manuscript preparation and final revision of the manuscript.

\section{Acknowledgements}

The authors would like to acknowledge the contributions of Laurence Drysdale, Ayanna Ogun and Shanice Weekes who assisted in the collection of data. Additionally, gratitude must be expressed to Dr. Arvind Babu Santosh for his contribution towards the development and review of the research proposal. The authors also thank Ms. Gabriela Soares Rech for her assistance with the analysis of the data.

\section{References}

1. Husain FA, Tatengkeng F. Oral Health-Related Quality of Life Appraised by OHIP-14 Between Urban and Rural Areas in Kutai Kartanegara Regency, Indonesia: Pilot Pathfinder Survey. Open Dentistry Journal. 2017; 11:557-564.

2. Zucoloto ML, Maroco J, Campos JA. Impact of oral health on health-related quality of life: a crosssectional study. BMC Oral Health. 2016;16 (1):55.

3. Slade GD, Spencer AJ. Development and evaluation of the oral health impact profile. Community Dental Health. 1994; 11(1):3.

4. Slade GD. Derivation and validation of a short-form oral health impact profile. Community dentistry and Oral Epidemiology. 1997; 25(4):284-90.

5. Who.int. (1948). Constitution. [online] Available at: https://www.who.int/about/who-we-are/constitution [Accessed 25 Oct. 2019].

6. Htun KCSS, Peltzer, K. Oral health-related quality of life among community dwelling middle-aged and older adults in an urban area in Magway region, Myanmar. Nagoya Journal of Medical Science. 2019; 81(1):103

7. Drachev S, Brenn T, Trovik T. Oral Health-Related Quality of Life in Young Adults: A Survey of Russian Undergraduate Students. International Journal of Environmental Research and Public Health. 2018; 15
(4):719.

8. Dahl KE, Wang NJ, Skau I, Öhrn K. Oral healthrelated quality of life and associated factors in Norwegian adults. Acta Odontologica Scandinavia. 2011;69(4):208-214.

9. Hodacová L, Smejkalová J, Cermáková E, Slezák R, Jacob V, Hlavácková E. Oral health-related quality of life in Czech population. Central European Journal of Public Health. 2010; 18(2):76.

10. Collins JR, Elías AR, Brache M, Veras K, Ogando G, Toro M, Rivas-Tumanyan S, Rajendra AB. Association between gingival parameters and Oral health-related quality of life in Caribbean adults: a population-based cross-sectional study. BMC oral health. 2019; 19

(1):234

11. World Health Organization (WHO). Oral Health Surveys, Basic Methods, 5th edition. Geneva: WHO, 2013.

12. Slade GD, Nuttall N, Sanders AE, Steele JG, Allen PF, Lahti, S. Impacts of oral disorders in the United Kingdom and Australia. British Dental Journal. 2005; 198(8): 489-493.

13. Sousa JL, Henriques A, Silva ZPD, Severo M, Silva S. Socioeconomic position and self-rated oral health in Brazil: results of the Brazilian National Health Survey. Caderno de Saude Publica. 2019; 35(6):e00099518e00099518.

14. Silva JV, Oliveira AG. Individual and contextual factors associated to the self-perception of oral health in Brazilian adults. Revista de Saude Publica. 2018; 52:29.

15. Al-Shammari KF, Al-Ansari JM, Al-Khabbaz AK, Dashti A and Honkala EJ. Self-reported oral hygiene habits and oral health problems of Kuwaiti adults. Medical Principles and Practice. 2007; 16(1):15-21.

16. Buunk-Werkhoven YA, Burrekers SY, Jongboer A, Quant DF, van Maanen-Schakel NW. Determinants of oral hygiene behavior in the Dominican Republic. International Dental Journal. 2011; 61(6):328-33.

17. Sanders, AE, Slade GD, Lim S, Reisine ST. Impact of oral disease on quality of life in the US and Australian populations. Community Dental and Oral Epidemiology. 2009; 37 (2):171-181.

18. Walsh T, Worthington HV, Glenny AM, Appelbe P, Marinho VC, Shi X. Fluoride toothpastes of different concentrations for preventing dental caries in children and adolescents. Cochrane database of systematic 
reviews. 2010(1).

19. Locker $D$, Allen F. What do measures of 'oral healthrelated quality of life' measure? Community Dental and Oral Epidemiology. 2007;35(6):401-411. 